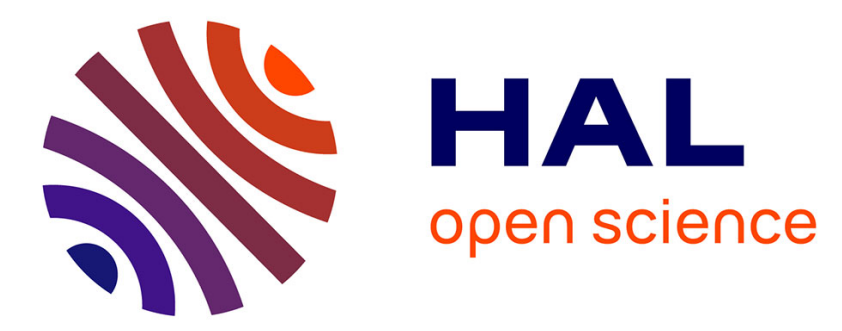

\title{
A comprehensive approach to study the resting-state brain network related to creative potential
}

\author{
Claire Deshayes, Véronique Paban, Marie-Hélène Ferrer, Béatrice
}

Alescio-Lautier, Caroline Chambon

\section{To cite this version:}

Claire Deshayes, Véronique Paban, Marie-Hélène Ferrer, Béatrice Alescio-Lautier, Caroline Chambon. A comprehensive approach to study the resting-state brain network related to creative potential. Brain Structure and Function, 2021, 226, pp.1743-1753. 10.1007/s00429-021-02286-9 . hal-03235568

\section{HAL Id: hal-03235568 https://hal.science/hal-03235568}

Submitted on 15 Nov 2021

HAL is a multi-disciplinary open access archive for the deposit and dissemination of scientific research documents, whether they are published or not. The documents may come from teaching and research institutions in France or abroad, or from public or private research centers.
L'archive ouverte pluridisciplinaire HAL, est destinée au dépôt et à la diffusion de documents scientifiques de niveau recherche, publiés ou non, émanant des établissements d'enseignement et de recherche français ou étrangers, des laboratoires publics ou privés. 


\author{
DESHAYES Claire ${ }^{\mathrm{a}, \mathrm{b}}$, PABAN Véronique $^{\mathrm{a}}$, FERRER Marie-Hélène ${ }^{\mathrm{c}}$, ALESCIO-LAUTIER Béatrice \\ $\mathrm{a}^{*}$, CHAMBON Caroline $^{\mathrm{a}}$
}

a Aix-Marseille Université, CNRS, LNC, NeuroMarseille, InCIAM, Marseille France; 3 Place Victor Hugo, 13331 Marseille Cedex 03, France.

${ }^{\mathrm{b}}$ Département Environnements Operationnels (ENOP), Unité Fatigue et Vigilance(UFV), Institut de Recherche, Biomédicale des Armées (IRBA), 91223 Brétigny-sur-Orge,France

c Departement Neurosciences et Contraintes Operationnelles (NCO), Institut de Recherche Biomedicale des Armées (IRBA) 91223 Brétigny-sur-Orge, Cedex, France

\begin{abstract}
*Corresponding author at:
Laboratoire de Neurosciences Cognitives - UMR 7291, Aix Marseille Univ \& Centre National de la Recherche Scientifique (CNRS), Centre Saint-Charles-Case B, 3, Place Victor Hugo, 13331 Marseille Cedex 03, France Tel: +33 (0) 413550883.
\end{abstract}

E-mail: Beatrice.alescio-lautier@univ-amu.fr

Structure Brain and Function (2021). https://doi.org/10.1007/s00429-021-02286-9

\begin{abstract}
Studies related to creativity generally investigate brain activity at rest using raw scores from only one creative task. However, considering all the factors that can impact the creative product, we believe that the creative potential of individuals must be evaluated to identify the associated resting-state brain networks. Moreover, studying the brain functional connectivity related to creativity processes should be considered in conjunction with cognitive functioning as both are composite phenomena. To test this assumption, in this exploratory study, we differentiated high- and low-creativity potential people with a cognitive functioning approach using structural equation modeling assuming an influence of working memory (WM) and analytical thinking on creativity assessed by the Torrance Tests of Creative Thinking. Then, we examined brain functional connectivity at rest and found that highly creative people had increased connectivity in the attentional network (AN), the default-mode network (DMN) and a decrease in the salience network (SN). Our findings highlight the involvement of the AN, which is very scarcely mentioned in the literature. We therefore linked this network to creative potential, which is consistent with cognitive theories suggesting that creativity is underpinned by attentional processes. Furthermore, studying creativity with an approach based on a model of cognitive functioning seems more consistent with how connectivity data are processed.
\end{abstract}

Key words: Creativity, fMRI, resting-state networks, cognitive processes.

\title{
Abbreviations:
}

Attentional network (AN); average variance extracted (AVE); Broadman Area (BA); default-mode network $(\mathrm{DMN})$; executive control network (ECN); partial least squares - structural equation modeling (PLS-SEM); response time (RT); sustained attention (SA); salience network (SN); Torrance Tests of Creative Thinking (TTCT); working memory (WM). 


\section{Introduction}

We owe everything to our creative ability: technology, research, medicine, facing the obstacles of life or even the entire human evolution depends on it. Creativity is defined by Lubart et al. (2003) and Bonnardel (2002) as "the ability to produce work that is both new and appropriate for the task". Several theories have been advanced to account for the cognitive mechanisms involved in creativity. Mednick (1962) hypothesized that creativity is supported by a flat associative hierarchy, i.e., the more remote the elements of a combination are from each other, the more creative the production becomes. In this theory, Mednick proposes that cognitive flexibility is a necessary process to propose creative combinations and thus new concepts. Mendelsohn, in 1976, defined people with high creative abilities as being able to maintain several parallel cognitive flows and to switch between them to use information by relying on attentional defocusing, which implies working memory (WM) (Abraham et al., 2018). Martindale, in 2007, characterized creativity as a cognitive and behavioral disinhibition. Indeed, he argued that creative people can switch between a focused and defocused state of mind, which would be sustained by attentional flexibility. It is interesting to note here that for Miyake et al. (2000), flexibility is one of the basic elements of WM. Based on all these theories, De Dreu et al. (2008) suggested that creativity is composed of two pathways: the flexibility pathway, which follows the models of Mednick and Mendelsohn, and the persistence pathway, which allows us to explore all solutions until the correct one is found. The latter is characterized by a focused and structured exploration of a few cognitive categories (Dietrich, 2004) as well as incremental research processes (Boden, 1998) that depend on WM.

An important notion that should be considered when studying creativity is analytical thinking, which has always been opposed to creative thinking. Indeed, creative thinking enables innovative solutions to be produced based on synthesis skills that require WM, while analytical thinking allows existing ideas to be evaluated and tested based on discrimination skills (Ansburg \& Hill, 2003). For Nijstad et al.
(2010), analytic thought alone cannot lead to creativity, so these two ways of thinking cannot occur at the same time.

From a brain function perspective, taskbased fMRI or EEG studies have investigated specific brain activations related to creativity (Benedek et al., 2020; Pidgeon et al., 2016; Rominger et al., 2020; Saggar et al., 2017; Stevens \& Zabelina, 2019; Takeuchi et al., 2020; Zhang et al., 2020). In these studies, the reported activations were registered during a creative task and were therefore specific to this task. Some works have also used a global approach to investigate differences between high- and lowcreative people using raw scores by studying brain connectivity at rest (Beaty, Kenett, et al., 2018; Beaty et al., 2019; Belden et al., 2020; Cousijn et al., 2014; Feng et al., 2019; Kenett et al., 2020; Schuler et al., 2019). The brain at rest is always activated, with some regions being coactivated at the same time. Resting-state networks reflect this coactivation, which can change over time. The work of many researchers (Allen et al., 2011; Raichle, 2011; D. Zhang \& Raichle, 2010) led to the identification of 7 main resting-state networks: the default-mode network $(\mathrm{DMN})$, the executive control network (ECN), the salience network (SN), the attentional network (AN), the sensorimotor networks $(\mathrm{SMN})$, the visual networks (VN) and the auditive networks (AUN). The DMN, ECN and $\mathrm{SN}$ are the main networks reported to be involved in creativity (Beaty, Chen, et al., 2018; Beaty et al., 2014; Belden et al., 2020). Surprisingly, the AN has not been highlighted, while attentional abilities have emerged from the current cognitive theories explaining the mechanisms underlying creativity.

Based on inconsistencies between cognitive theories highlighting attention as a key process in creative thinking and resting-state fMRI data that have not shown the AN to be the most important network in creative people, in the present exploratory study, we propose a different approach for studying not the creative product but rather the upstream cognitive processes that may participate in the creative potential of an individual. The most common approach used to study brain activation associated with creativity is to distinguish between high- and low-creative people on the basis of their raw scores in a creative task. We believe that an approach based 
on a model of cognitive functioning that would allow a more comprehensive understanding of creative potential would be more relevant than the use of raw scores.

To test this assumption, we used partial least squares structural equation modeling (PLSSEM). As indicated above, WM seems to be important for creativity, while analytical thinking is not. Indeed, our cognitive model questioned the extent to which each of these two cognitive

\section{Method}

\section{Participants}

We recruited 45 healthy subjects between 20 and 50 years of age (mean age $\pm \mathrm{SD}=34.12$ \pm 8.84 years; $\mathrm{M} / \mathrm{W}=22 / 23$; mean years of study \pm $\mathrm{SD}=14.13 \pm 3.25)$. None of the participants reported any clinical or psychological disorders. In accordance with the Declaration of Helsinki, all the participants were fully informed of the experiment and provided their consent.

\section{Cognitive assessment}

Cognitive assessment was performed to evaluate the creative potential of the subjects as well as their WM and analytical thinking skills. To assess the creative potential, we used selected verbal and figural tasks of the TTCT form A. We selected verbal imagination tasks 1 to 3,5 and 6 and imagination with drawings tasks 1 to 3 . Tasks were scored following the guidelines derived from the TTCT (Torrance, 2008, 2017). For each task, we considered flexibility, fluence, originality and elaboration score. WM was evaluated through the sustained attention (SA) task from the TAP battery (Zimmermann and Fimm, 1994). In this task, geometric figures of different shapes, sizes and colors are presented to the subjects. These figures appear one after the other in the middle of the screen, and the subject must press a button as quickly as possible when 2 consecutive figures are of the same shape or color. This task requires a great deal of WM for the updating that must be done at each trial. We measured the response times (RTs) and the percentages of correct answers. Analytical thinking was assessed with Luria problem solving, where we measured the percentage of correct answers, and with a modified abilities may explain creative performance evaluated via the Torrance Tests of Creative Thinking (TTCT). We differentiated high- and low-creative potential people based on their composite scores in the path model. Then, an fMRI analysis at rest was performed to isolate the difference in brain functional connectivity patterns between individuals with high- and lowcreative potential.

computerized version of the Tower of Hanoi developed by the Biomedical Research Institute of the Armies (IRBA, Bretigny sur Orge, France). For the latter test, there are 5 difficulty levels corresponding to 1 to 5 disks that can be transferred among three bases presented on the screen. The disks form a pyramid on the left base, and the goal is to transfer the pyramid to the right base with a minimum number of moves. When doing so, the participant must follow several rules: only the disk on the top of the stack can be moved, only one disk can be moved at a time, and a larger disk cannot be placed on a smaller one. We recorded the RT and the number of moves.

\section{PLS-SEM}

PLS-SEM is an advanced statistical method based on exploratory techniques (Bollen \& Lennox, 1991) that performs adequately with small sample sizes (Hair et al., 2014). We have previously described the method in Paban et al. (2018). We used this method to evaluate the correlations between creativity and WM and analytic thought. PLS-SEM first analyzes the measurement model elaborated from indicator variables and then examines the structural model performed from our construct. The path model is translated into a set of equations describing a measurement model and a structural model (Haenlein \& Kaplan, 2004). Briefly, in a first step, PLS-SEM validates the measurement model by assessing internal consistency, convergent validity (composed of the average variance-extracted scores for each construct and the outer landing for each indicator) and discriminant validity (composed of crosslanding). In a second step, PLS-SEM examines the structural model performed from latent variables by assessing the quality of relationships measured by the $\mathrm{R}^{2}$ metric (Riou et al., 2016). 
Participant separation

An ascending hierarchical classification analysis was performed to separate participants based on their score in the path model. Briefly, similarities between latent variables' scores of every pair of participants were evaluated by calculating the Euclidean distance between participants. Participants were grouped into clusters using Ward's aggregation method, which links pairs of subjects who are close together into binary clusters forming a hierarchical tree. Finally, cutting the tree at the maximum dissimilarity provided two distinct clusters highlighting two groups of subjects.

Statistical comparison of path coefficients between the 2 groups was performed using XLSTAT software (www.xlstat.com), which offers multigroup comparison methods in the framework of PLS path modeling presented by Goles and Chin in 2005. An adapted t-test based on bootstrap standard errors was used. Statistical significance was set at $p \leq 0.05$. Then, we considered the composite score calculated by the PLS-SEM model on the latent variable of creativity, and we calculated Student's t-test between the two groups of participants.

\section{MRI acquisition}

All subjects were scanned in a $3 \mathrm{~T}$ Siemens Prisma scanner (European Center for Research in Medical Imaging; CERIMED, Marseille, France) equipped with a circular polarized head coil. Images were acquired in the axial plane, parallel to the anterior-posterior commissure axis and covering the entire brain. We acquired T1 images (magnetization-prepared rapid gradient-echo (MPRAGE) sequence; $\mathrm{TR}=2.4 \mathrm{sec}, \mathrm{TE}=2.28 \mathrm{msec}$, flip angle $=8^{\circ}$, $\mathrm{FOV}=256.0 \mathrm{~mm}$, voxel size $=0.8 \mathrm{~mm}$ isotropic, and matrix $=256 \times 256$ ), and for the functional images, participants were asked to rest for $15 \mathrm{~min}$ with their eyes closed but not fall asleep $(\mathrm{TR}=$ $780 \mathrm{msec}, \mathrm{TE}=30 \mathrm{msec}$, flip angle $=54^{\circ}, \mathrm{FOV}$ $=210 \mathrm{~mm}$, voxel size $=2.5 \mathrm{~mm}$ isotropic, matrix $=210 \times 210$, slice thickness $=2.5 \mathrm{~mm}, 0.75 \mathrm{~mm}$ gap, and 1145 volumes). At the end of the scan, we asked participants whether they had fallen asleep during this 15 min resting-state period. None of them had fallen asleep. One subject did not close his eyes during the resting state, and so we discarded his data from the fMRI analyses.

\section{MRI preprocessing and processing}

Images from each subject $(n=44)$ were preprocessed using the MATLAB toolbox SPM12 (MATLAB v18b) to correct distortion and movements (Voxel Distortion Maps were calculated based on individual field maps and then realigned and unwarped), and the anatomic data were realigned in the same space (coregister estimate) and segmented according to different brain tissues (segments: gray matter, white matter, LCR, bone tissue, soft tissue and residual tissue). Following this step, we normalized our data into the space defined by the Montreal Neurological Institute (MNI) using the DARTEL toolbox. Finally, the functional images were smoothed with a Gaussian Kernel of $6 \times 6 \times 6 \mathrm{~mm}$ to correct anatomical-functional variability. Because we were interested in the DMN, the $\mathrm{ECN}$, the $\mathrm{SN}$ and the AN, we decided to use the ROIs derived from Allen et al. (2011) (DMN, AN) and Raichle (2011) (DMN, ECN, SN) (cf. Table 1). Masks were created for each selected ROI from the DMN, ECN, SN and AN (MarsBar). In the Conn toolbox (Conn toolbox $v 17 \mathrm{f}$ ), images were bandpass filtered at $0.009 \mathrm{~Hz}$ - $0.08 \mathrm{~Hz}$ to reduce the effect of low-frequency drift and high-frequency noise. The Artifact Detection Toolbox (ART) was used to identify outliers. For denoising, white matter, cerebrospinal fluid, motion and ART outliers were taken as confounders and removed from the signal by regression (Behzadi et al., 2007). Finally, a functional connectivity analysis was performed using an ROI-to-ROI analysis (the DMN, ECN, AN and SN have 105, 6, 171 and 21 connections to be tested, respectively). The firstlevel analysis was performed to define functional connectivity measures of each pair of ROIs for each subject. Then, still in the Conn toolbox, the second-level analysis was performed to compare functional connectivity between high- and lowcreative potential people for the four functional networks by a Fisher test (two-sided analysis, a Benjamin-Hochberg method false discovery rate-corrected $p(p-F D R) \leq 0.05)$. We consider the cognitive data from the WM and analytic thought as covariable of non-interest, in order to remove the signal explain by this variable from the second level analysis. 


\begin{tabular}{|c|c|c|c|c|c|}
\hline Region & Laterality & BA & $\mathbf{x}$ & $\mathbf{y}$ & $\mathbf{z}$ \\
\hline \multicolumn{6}{|l|}{$D M N$} \\
\hline inferior parietal gyrus & $\mathrm{L}$ & BA 39 & -46 & -66 & 30 \\
\hline Inferior parietal gyrus & $\mathrm{R}$ & BA39 & 49 & -63 & 33 \\
\hline Inferior temporal gyrus & $\mathrm{L}$ & BA21 & -61 & -24 & -9 \\
\hline Inferior temporal gyrus & $\mathrm{R}$ & BA21 & 58 & -24 & -9 \\
\hline Medial dorsal thalamus & $\mathrm{Bi}$ - lateral & BA50 & 0 & -12 & 9 \\
\hline Precuneus & $\mathrm{Bi}$ - lateral & BA7 & 1 & -64 & 43 \\
\hline Posterior cingulate cortex & Bi lateral & BA23 & 0 & -52 & 22 \\
\hline Angular gyrus & $\mathrm{L}$ & BA 39 & -43 & -69 & 33 \\
\hline Angular gyrus & $\mathrm{R}$ & BA39 & 47 & -66 & 32 \\
\hline Anterior cingulate cortex & $\mathrm{Bi}$ - lateral & BA32 & 0 & 41 & 4 \\
\hline Middle cingulate cortex & $\mathrm{Bi}$ - lateral & BA32 & 0 & 21 & 40 \\
\hline Medial frontal gyrus & Bi- lateral & BA10 & -1 & 45 & -9 \\
\hline Inferior frontal gyrus & $\mathrm{R}$ & BA47 & 32 & 22 & -15 \\
\hline Middle frontal gyrus & $\mathrm{R}$ & BA8 & 26 & 33 & 41 \\
\hline Middle frontal gyrus & $\mathrm{L}$ & BA8 & -26 & 26 & 42 \\
\hline \multicolumn{6}{|l|}{$E C N$} \\
\hline Dorsal medial PFC & Bi- lateral & BA8 & 0 & 24 & 46 \\
\hline Anterior PFC & $\mathrm{L}$ & BA6 & -44 & 45 & 0 \\
\hline Anterior PFC & $\mathrm{R}$ & BA6 & 44 & 45 & 0 \\
\hline Superior Parietal & $\mathrm{L}$ & BA39 & -50 & -51 & 45 \\
\hline \multicolumn{6}{|l|}{$A N$} \\
\hline Cingulate gyrus & Bi-lateral & BA 32 & 0 & 22 & 45 \\
\hline Inferior parietal gyrus & $\mathrm{L}$ & BA40 & -47 & -57 & 39 \\
\hline Inferior parietal gyrus & $\mathrm{R}$ & BA 39 & 42 & -56 & 42 \\
\hline Intra- parietal sulcus & $\mathrm{R}$ & BA 7 & 27 & -65 & 44 \\
\hline Middle frontal gyrus & $\mathrm{L}$ & BA 8 & -27 & 24 & 49 \\
\hline Middle frontal gyrus & $\mathrm{R}$ & BA 8 & 34 & 24 & 44 \\
\hline Inferior frontal gyrus & $\mathrm{L}$ & BA 45 & -43 & 24 & 21 \\
\hline Superior frontal gyrus & $\mathrm{L}$ & BA 9 & -32 & 38 & 39 \\
\hline Superior frontal gyrus & $\mathrm{R}$ & BA 9 & 33 & 39 & 35 \\
\hline Precuneus & $\mathrm{L}$ & BA 31 & -6 & -52 & 37 \\
\hline Precuneus & Bi-lateral & BA 7 & 0 & -53 & 61 \\
\hline Middle temporal gyrus & $\mathrm{L}$ & BA 21 & -62 & -37 & -12 \\
\hline Middle temporal gyrus & $\mathrm{R}$ & BA 21 & 64 & -39 & -11 \\
\hline Superior temporal gyrus & $\mathrm{L}$ & BA 22 & -56 & -48 & -18 \\
\hline Superior temporal gyrus & $\mathrm{R}$ & BA 22 & 57 & -44 & 11 \\
\hline Angular gyrus & $\mathrm{L}$ & BA 39 & -33 & -64 & -31 \\
\hline Precentral gyrus & $\mathrm{R}$ & BA 6 & 51 & 2 & 50 \\
\hline Insula & $\mathrm{L}$ & BA13 & -46 & 15 & -5 \\
\hline Insula & $\mathrm{R}$ & BA 13 & 45 & 18 & -6 \\
\hline \multicolumn{6}{|l|}{$S N$} \\
\hline Dorsal anterior cingulate & Bi- lateral & BA32 & 0 & 21 & 36 \\
\hline Anterior PFC & $\mathrm{L}$ & BA10 & -35 & 45 & 30 \\
\hline Anterior PFC & $\mathrm{R}$ & BA9 & 32 & 45 & 30 \\
\hline Insula & $\mathrm{L}$ & BA13 & -41 & -3 & 6 \\
\hline Insula & $\mathrm{R}$ & BA13 & 41 & 3 & 6 \\
\hline Lateral parietal gyrus & $\mathrm{L}$ & BA39 & -62 & -45 & 30 \\
\hline Lateral parietal gyrus & $\mathrm{R}$ & BA39 & 62 & -45 & 30 \\
\hline
\end{tabular}




\section{Results}

\section{Cognitive profile}

The measurement model was constructed from data including all the participants $(\mathrm{N}=45)$ and included three reflective constructs: WM, analytic thought, and creativity. The reliability and validity results are given in Table 2 . The validity of the measurement model was assessed by internal consistency, convergent validity and discriminant validity. Internal consistency was calculated using the composite reliability of the items. The internal consistency measures, as indexed by the composite reliability, ranged approximately 0.80 , exceeding the recommended threshold value of 0.70 . The average variance extracted (AVE) scores for each construct and the outer loading of each indicator were examined and represented the convergent validity. Discriminant validity was evaluated by assessing the cross loading. The convergent validity was acceptable, as AVE was above 0.5 for all three constructs. Each item's factor loading was significant $(\mathrm{p}<0.05$, data not shown), and all but two were above 0.6 .

\begin{tabular}{|c|c|c|c|c|c|c|}
\hline \multirow[b]{2}{*}{$\begin{array}{l}\text { Latent } \\
\text { variables }\end{array}$} & \multirow[b]{2}{*}{$\begin{array}{l}\text { Composite } \\
\text { reliability }\end{array}$} & \multirow[b]{2}{*}{ Indicators } & \multicolumn{3}{|c|}{ Outer loadings and cross loadings } & \multirow[b]{2}{*}{ AVE } \\
\hline & & & WM & $\begin{array}{l}\text { Analytic } \\
\text { Though }\end{array}$ & Creativity & \\
\hline WM & 0.84 & $\begin{array}{r}\text { SA task } \\
\text { Running times 0-5 min } \\
\% \text { correct answers } 0-5 \mathrm{~min} \\
\text { Running times 5-10 min } \\
\% \text { correct answers 5-10 min } \\
\text { Running times } 10-15 \mathrm{~min}\end{array}$ & $\begin{array}{l}0.86 \\
0.56 \\
0.77 \\
0.54 \\
0.81\end{array}$ & $\begin{array}{c}0.07 \\
0.45 \\
-0.04 \\
0.49 \\
0.09 \\
\end{array}$ & $\begin{array}{l}-0.18 \\
-0.14 \\
-0.12 \\
-0.06 \\
-0.12 \\
\end{array}$ & 0.52 \\
\hline $\begin{array}{l}\text { Analytic } \\
\text { though }\end{array}$ & 0.78 & \begin{tabular}{|cc} 
Luria & \\
Hanoi & $\%$ Correct answers \\
& \\
& Running times level 1 \\
& Running times level 2 \\
& Running times level 4
\end{tabular} & $\begin{array}{l}0.32 \\
0.32 \\
0.14 \\
0.19\end{array}$ & $\begin{array}{l}0.71 \\
0.62 \\
0.70 \\
0.63\end{array}$ & $\begin{array}{l}-0.30 \\
-0.21 \\
-0.12 \\
-0.14\end{array}$ & 0.50 \\
\hline Creativity & 0.82 & \begin{tabular}{|rr} 
TTCT figurative & \\
& $\begin{array}{r}\text { fluency } \\
\text { flexibility } \\
\text { originality }\end{array}$ \\
TTCT verbal & fluency \\
& originality
\end{tabular} & $\begin{array}{l}0.22 \\
0.31 \\
0.14 \\
0.31 \\
0.22\end{array}$ & $\begin{array}{l}-0.29 \\
-0.36 \\
-0.23 \\
0.14 \\
-0.14\end{array}$ & $\begin{array}{l}0.95 \\
0.91 \\
0.91 \\
0.61 \\
0.62\end{array}$ & 0.66 \\
\hline
\end{tabular}

Table 2 Assessment of the measurement model: internal consistency (composite reliability), convergent validity (loading and AVE), and discriminant validity (cross loading). Items in bold represent loadings $>0.50$ threshold.

As the validity of the measurement model was assured, we used an ascending hierarchical classification method to separate subjects, which provided 2 distinct clusters corresponding to group $1(\mathrm{~N}=25, \mathrm{~W} / \mathrm{M}=14 / 11)$ and group 2 $(\mathrm{N}=20, \mathrm{~W} / \mathrm{M}=9 / 11)$ (Fig. 1) no significant differences were observed between the two groups in term of age, sex and education level (Table 3). Therefore, we did not use any of these variables as a co-factor for fMRI processing. When latent variable creativity scores were considered, the data showed that the two groups performed differently: group 1 (high-creative potential group) had a higher creative score than group 2 (low-creative potential group) (Fig. 2). Student's t-test computed on this latent variable score between the two groups yielded a 
significant effect of group $(\mathrm{t}(43)=4.09$;

$\mathrm{p}<0.0001)$.

Dendrogram

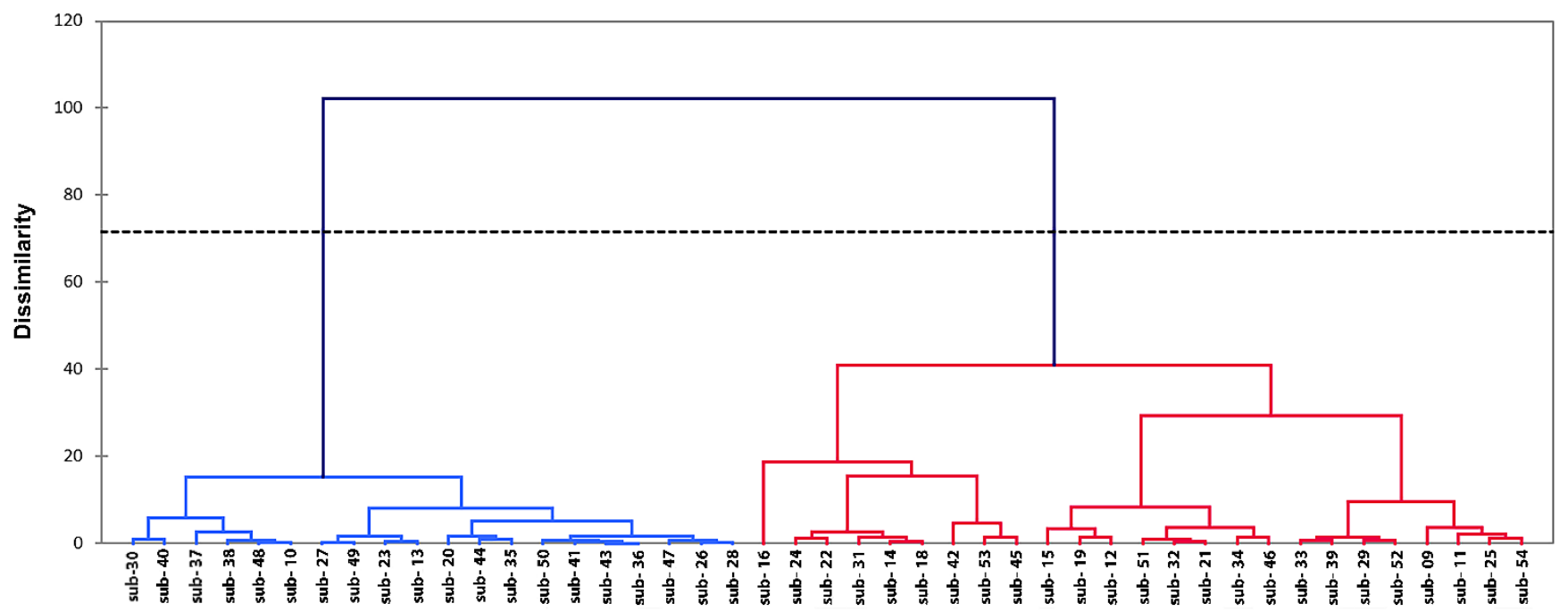

Fig. 1 Dendrogram of the hierarchical tree of clustering. We cluster the subject in two groups based on their cognitive results of the PLS- SEM with a Ward's aggregation method.

\begin{tabular}{|c|c|c|c|c|c|c|}
\hline & \multicolumn{2}{|c|}{ Age } & \multicolumn{2}{|c|}{ Years of education } & \multicolumn{2}{|c|}{ Gender } \\
\hline & Mean & $S t d$ & Mean & $S t d$ & Mean & Std \\
\hline High Creative potential (Group 1) & 36,08 & 8,18 & 15,28 & 3,46 & 0,56 & 0,51 \\
\hline Low Creative potential (Group 2) & 31,6 & 10,47 & 13,65 & 1,95 & 0,45 & 0,51 \\
\hline T-Test & \multicolumn{2}{|c|}{0,11} & \multicolumn{2}{|c|}{0,053} & \multicolumn{2}{|c|}{0,47} \\
\hline
\end{tabular}

Table 3 Effects of age, years of education and gender ( 0 for men and 1 for women) between the two groups.

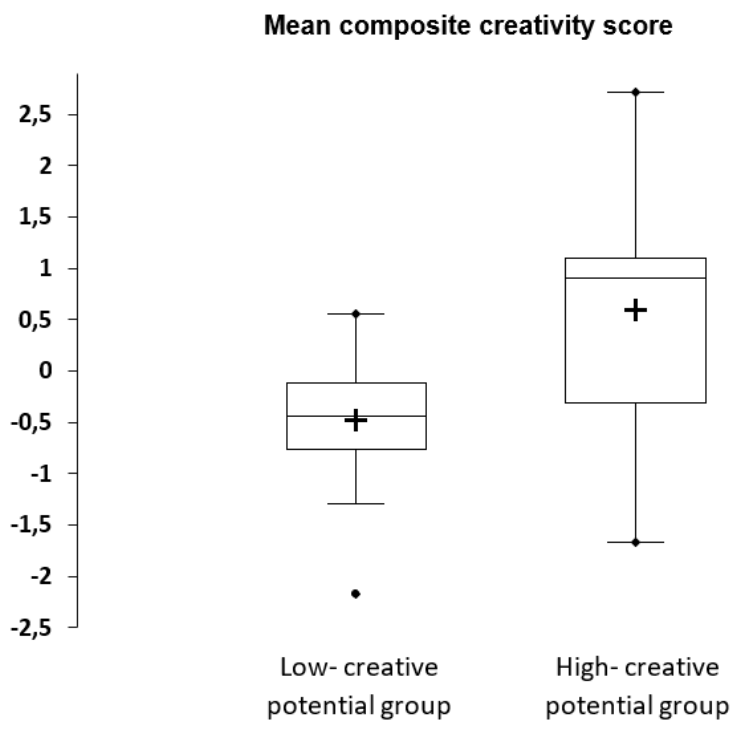

Fig. 2 Mean composite creative score. Low creative potential group is in the left and high creative potential group is in the right

Regarding the structural model in the two groups, the quality of the relationships was measured by the R2 metric, which reflects the level of the explained variance of the composites. The effect size f2 and Stone-Geisser's Q2, assessing the model predictive power, were computed (Riou et al., 2016). In the high-creative potential group, the results showed that the model was statistically significant, $F=8.63$, $\mathrm{p}=0.003$, with an $\mathrm{R}^{2}$ value of 0.50 , indicating that 
a substantial amount of the variance was explained. Both paths yielded a significant effect. WM showed a positive correlation, whereas analytic thought showed a negative correlation with creativity $(\mathrm{r}=0.403 ; \mathrm{p}=0.014$ and $\mathrm{r}=-0.535$; $\mathrm{p}=0.003$, respectively) (Fig. 3a). The effect size of each path calculated through $\mathrm{f}^{2}$ values revealed a high effect of both WM $\left(\mathrm{f}^{2}=0.44\right)$ and analytic thought $\left(\mathrm{f}^{2}=0.69\right)$ on creativity (Table 4$)$. The model's predictive power $\left(\mathrm{Q}^{2}\right.$ index $)$ for creativity was 0.19 . In the low-creative potential group (Fig. 3b), the model was statistically significant, $F=6.74, p=0.005$, with substantial explained variance of $\mathrm{R}^{2}=0.38$. In this model, only analytic thought was significant, and it was negatively correlated with creativity $(\mathrm{r}=-0.582$, $\mathrm{p}=0.013)$. The effect size of analytic thought calculated through $\mathrm{f}^{2}$ values revealed a high effect $\left(\mathrm{f}^{2}=0.33\right)$ on creativity (Table 4$)$. The model predictive power $\left(\mathrm{Q}^{2}\right.$ index $)$ of creativity was low at 0.08 .

The results of the multi-group t-test showed a significant difference between the high- and low-creative potential groups for the path coefficient related to $\mathrm{WM}$ and creativity $(\mathrm{t}(43)=2.036 ; \mathrm{p}=0.049)$.

\begin{tabular}{r|c|c} 
Paths & $\mathbf{f}^{2}$ & Magnitude of the effect \\
\hline Model of High creative potential group & & \\
Working Memory on Creativity & 0.44 & High \\
Analytic though on Creativity & 0.69 & Substantial \\
\hline Model of Low creative potential group & & \\
Working Memory on Creativity & 0.07 & Low \\
Analytic though on Creativity & 0.33 & High
\end{tabular}

Table 4 Effect size of the structural model paths.

3.a)

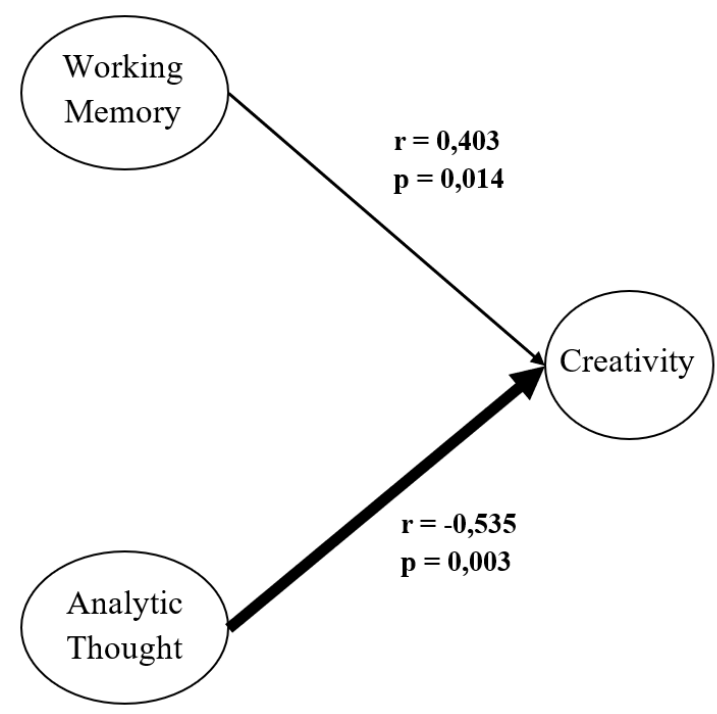

3.b)

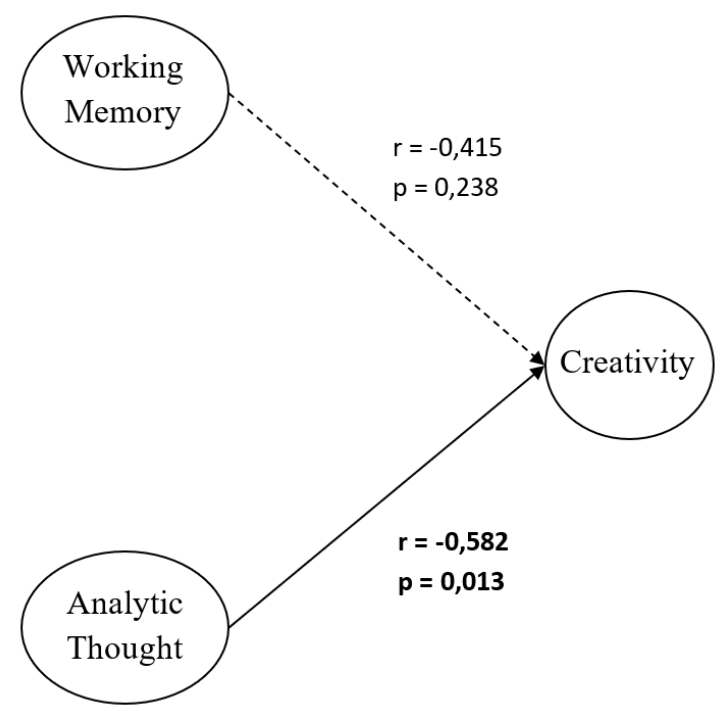

Fig. 3 Structural model of the direct effects of working memory, analytic thought, and creativity. a) High creative potential group; b) Low Creative potential group. Big row for high significative correlation, normal row for significant correlation and discontinuing row for non-significant correlation 


\section{Functional connectivity}

The functional connectivity analysis showed no difference in the ECN between the high-creative potential group and the lowcreative potential group. However, significant changes in the AN, DMN and SN (p-FDR <0.05) were identified (Fig. 4). In the AN (Fig. 4.a), the right intraparietal sulcus showed enhanced connectivity with the left inferior parietal gyrus $(\mathrm{t}(33)=4.60, \mathrm{p}-\mathrm{FDR}=0.0011)$, the left precuneus $(\mathrm{t}(33)=3.87, \mathrm{p}-\mathrm{FDR}=0.0041)$, the left middle temporal gyrus $(\mathrm{t}(33)=3.75$, $\mathrm{p}-\mathrm{FDR}=0.0041)$, the right middle temporal gyrus $(\mathrm{t}(33)=3.47$, $\mathrm{p}$ $\mathrm{FDR}=0.0067)$, and the right inferior parietal gyrus $(t(33)=2.94, p-F D R=0.0217)$. The right inferior parietal gyrus showed enhanced functional connectivity with the left middle frontal gyrus $(\mathrm{t}(33)=3.20$, $\mathrm{p}-\mathrm{FDR}=0.0444)$, the left precuneus $(\mathrm{t}(33)=2.85), \mathrm{p}-\mathrm{FDR}=0.0444)$, the right superior temporal gyrus $(\mathrm{t}(33)=2.55$, $\mathrm{p}$ $\mathrm{FDR}=0.0483)$, the bilateral precuneus $(\mathrm{t}(33)=$ 2.54, $\mathrm{p}-\mathrm{FDR}=0.0483)$, and the left inferior parietal gyrus $(\mathrm{t}(33)=2.54$, $\mathrm{p}-\mathrm{FDR}=0.0483)$. The right middle temporal gyrus showed enhanced functional connectivity with the bilateral precuneus $(\mathrm{t}(33)=4.04, \mathrm{p}-\mathrm{FDR}=0.0054)$ and the left middle frontal gyrus showed enhanced connectivity with the left superior frontal gyrus $(\mathrm{t}(33)=2.97, \mathrm{p}-\mathrm{FDR}=0.0495)$. In the DMN (Fig. 4.b), there was an increased connectivity between the bilateral precuneus and the right inferior temporal gyrus $(\mathrm{t}(33)=3.65$, $\mathrm{p}$ FDR=0.0124). Finally, the SN (Fig. 4.c) showed a decreased connectivity between the left lateral parietal gyrus and the right insula $(\mathrm{t}(33)=-2.94$, $\mathrm{p}-\mathrm{FDR}=0.0361$ ). 4.a)

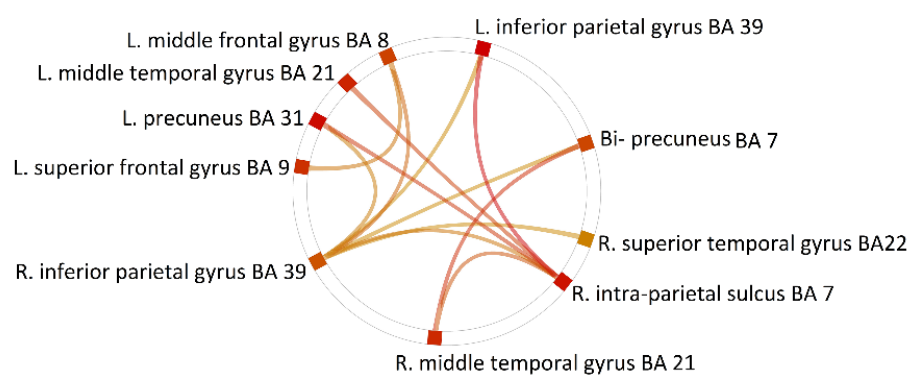

4.C) ROI-to-ROI effects: $-2.94 \quad 2.94$
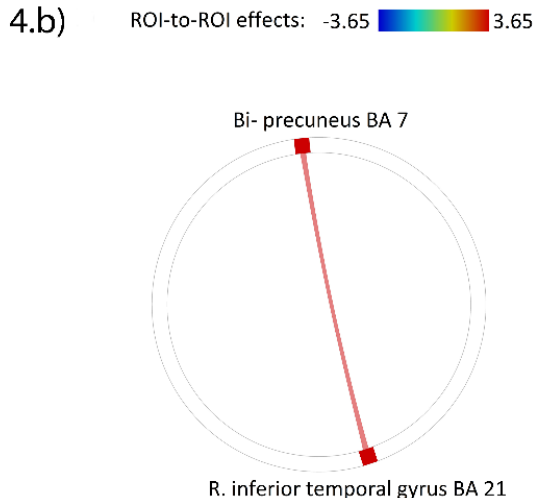

L. lateral parietal gyrus BA 39

Fig. 4 Contrast of functional connectivity between the high and the low creative people (High creative potential > Low creative potential). a) Attentional Network; b) Default Mode Network; c) Salience Network. Red line represents positive correlation and blue line corresponds to negative correlation. The degree of red or blue correspond to the correlation's level. 


\section{Discussion}

The aim of this study is to show that by studying creative potential rather than studying creativity through a single measure of creativity, we can highlight the involvement of the AN, which is highly in line with the literature on creativity showing that attentional ability underpins creativity. This exploratory study allowed us to differentiate high- and low-creative potential subjects based on their cognitive functioning using PLS-SEM. To the best of our knowledge, this is the first time that such an approach has been used in this context. The model considered three latent variables: WM, analytical thinking and creativity. We have seen that for both groups, analytical thinking is negatively correlated with creativity, meaning that the more creative a person is, the worse its analytical thinking is. This result agrees with data from Nijstad et al. (2010), showing that analytic thought makes it possible to find simple ideas linked to pre-existing concepts but does not lead to something original. In parallel, our cognitive results show that WM is positively correlated with creativity but only for the high-creative potential group. This result is in favor of the involvement of WM in the creative process, in line with the model of the dual pathway of creativity (De Dreu et al., 2008). However, we also showed that in lower-creative potential people, no correlation exists between WM and creativity. This means that neither WM promotes nor hinders creativity. Thus, the relationship between WM and creativity is not linear. An explanation would be that WM will operate in conjunction with another cognitive process that is not included in our model to foster creativity. Further studies will be necessary to confirm this assumption.

Regarding functional connectivity differences between high- and low-creative potential people, we observed enhanced connectivity in both the AN and the DMN. The more activated regions in the AN show two nodes, the right intraparietal sulcus (Brodmann area (BA) 7) and the right inferior parietal gyrus (BA 39). These areas communicate more with regions in the left middle temporal gyrus (BA
21), left middle and superior frontal gyrus (respectively BA 8 and BA 9), the bilateral and left precuneus (respectively BA 7 and BA 31), the left inferior parietal gyrus (BA 40) and the right superior temporal gyrus (BA 22). All these areas are involved in creativity and particularly in insight (Barbey et al., 2013; Ding et al., 2015; Pidgeon et al., 2016; Tik et al., 2018; Wu et al., 2016). Moreover, the precuneus is primarily involved in the retrieval of semantic information from WM and particularly for insight processes (Cavanna \& Trimble, 2006). Notably, BAs 7and 21 also show increased connectivity in the DMN, which is associated with WM and insight (Ogawa et al., 2018; H. Takeuchi et al., 2012). BA 7, which, in our study, is common in AN and DMN in more creative people, is associated with object recognition by touch (stereognosis) and is a very important node in visual mental rotation (Harris et al., 2000; Podzebenko et al., 2005). Moreover, BA 21 is involved in visual object recognition, and BA 39 is an associative area involved in perception, vision and reading. Interestingly, Mechelli (2004) showed, by comparing a visual perception task and a visual mental imaging task, that all these regions form the visual mental imaging network. This pattern of activation in creative people leads us to hypothesize that there is an active link between mental imagery, insight processes and WM.

Our results also show modified functional connectivity within the $\mathrm{SN}$ for those with higher creative potential. There is a decrease functional connectivity in SN between the lateral parietal lobe (BA 39) and the right insula (BA 13). The latter structure is involved in insight (Shen et al., 2016) and also in a lot of cognitive function, especially decision making (Uddin et al., 2017). Furthermore, given that the lateral parietal (BA 39) is involved in episodic memory recall (Benedek et al., 2014) and that in order to make decisions, we must to base them on our lived experience (Madore et al., 2015), we think that this decrease in connectivity between these two structures, among people with greater creative potential, would imply that decision making takes less account of the person's past experiences to allow creative responses to emerge. This assumption is coherent with what Gupta et al., (2012) suggest, they say that, to be 
original we need to inhibit what has already been done, what is common, in order to go for something new.

Taken together, our cognitive and functional connectivity results showing a positive correlation between WM and creativity, as well as greater functional connectivity within the AN and the DMN in high-creative potential people, suggest that these two networks are key points in creativity through WM processes involving mental imagery and insight processes. We have also highlighted a decreased connectivity within the $\mathrm{SN}$, suggesting a difference in the way decision-making is done among high- creative potential people, it takes less account of their experience to go through something new. Notably, our results, although largely in line with the literature, stress the involvement of the AN in high-creative potential people, which is not commonly highlighted in other studies, and not the involvement of the ECN, which is usually emphasized. This circumstance can be explained by the fact that in the literature, high- and low-creative people are mainly distinguished on the basis of a single task (an alternative uses task or the remote associative task); consequently, the results for functional connectivity are related to functioning in these specific tasks, precluding characterization of the resting-state functional connectivity related to creative potential. Moreover, in this work, we used a cognitive functioning approach; thus, we think that the results of functional connectivity reflect a more comprehensive representation of creative potential. This interpretation is consistent with Riegel et al's statement (1966) that reducing an interpretation of creativity to the lowest level of associative processes is not necessary. Furthermore, we think that when the subjects' differentiation was based on correlation of raw scores, such as in the literature, the focus was made on cognitive processes strictly necessary for the completion of the specific creative task. When the subjects' differentiation was approached by a cognitive functioning model based on the correlation of composite scores, as in our study, the focus was on cognitive processes underlying creative potential.

\section{General conclusion and limitations}

In conclusion, the results from this exploratory study clearly show that the classification of individuals as having high or low creative potential by highlighting different aspects of creativity is associated with specific features of resting-state brain functional connectivity, as described above. We believe that approaching the creativity levels of individuals through creative potential using a cognitive functioning model may be more relevant than previous methods of studying creativity and associated cerebral networks. Our results show that the AN and the DMN seem to be essential for creativity expression through WM processes involving mental imagery, a focus that has never been highlighted to date.

However, our results must be confirmed with a larger sample size in a future confirmatory study. Likewise, our cognitive model is limited and would require further elaboration to determine the relationships more accurately between mental imagery, WM, insight and creativity from both cognitive and functional viewpoints.

\section{Acknowledgments}

We thank Jean-Luc Anton and Julien Sein of the European Centre for Research in Medical Imaging (CERIMED) in Marseilles (France) for their technical assistance.

\section{Funding}

This work was supported by a grant (ANR-15CE19-0026-01) co-funded by the French National Research Agency (ANR) and the CNSA (National Solidarity Fund for Autonomy).

\section{Conflicts of interest}

The authors declare that the research was conducted in the absence of any commercial or financial relationship that could be construed as a potential conflict of interest.

The opinions or assertions expressed herein are the private views of the authors and are not to be regarded as official or as reflecting the views of the French Military Health Service. 


\section{Ethics approval}

The study was approved by the national research ethics committee (CPP $\mathrm{n}^{\circ}$ 125-14) and was performed in accordance with the ethical standards described in the Declaration of Helsinki.

\section{Consent to participate}

Informed consent was obtained from all individual participants included in the study.

\section{Code availability}

PLS-SEM is available at www.xlstat.com.

SPM12 is a Matlab toolbox available at https://www.fil.ion.ucl.ac.uk/spm/software.

\section{$\underline{\text { Reference }}$}

Abraham, A., Rutter, B., Bantin, T., \& Hermann, C. (2018). Creative conceptual expansion: A combined fMRI replication and extension study to examine individual differences in creativity. Neuropsychologia, 118, 29-39. https://doi.org/10.1016/j.neuropsychologia.2 018.05.004

Allen, E. A., Erhardt, E. B., Damaraju, E., Gruner, W., Segall, J. M., Silva, R. F., Havlicek, M., Rachakonda, S., Fries, J., Kalyanam, R., Michael, A. M., Caprihan, A., Turner, J. A., Eichele, T., Adelsheim, S., Bryan, A. D., Bustillo, J., Clark, V. P., Feldstein Ewing, S. W., ... Calhoun, V. D. (2011). A Baseline for the Multivariate Comparison of Resting-State Networks. Frontiers in Systems Neuroscience, 5(2), 23. https://doi.org/10.3389/fnsys.2011.00002

Ansburg, P. I., \& Hill, K. (2003). Creative and analytic thinkers differ in their use of attentional resources. Personality and Individual Differences, 34(7), 1141-1152. https://doi.org/10.1016/S01918869(02)00104-6

Barbey, A. K., Colom, R., \& Grafman, J. (2013). Architecture of cognitive flexibility revealed by lesion mapping. NeuroImage, 82, 547554.

https://doi.org/10.1016/j.neuroimage.2013.05 .087
Conn is a software based on MATLAB and is available at https://www.nitrc.org/projects/conn.

\section{Author contribution statements}

C. Deshayes and B. Alescio-Lautier developed the study concept; C. Deshayes, B. AlescioLautier, M. H Ferrer and C. Chambon contributed to the study design; C. Deshayes performed the experiments; C. Deshayes and V. Paban analyzed the data and prepared the figures; C. Deshayes and B. Alescio-Lautier interpreted the results of the experiments and wrote the manuscript. C. Chambon and V. Paban provided critical revisions. All authors approved the final version of the manuscript for submission.

Beaty, R. E., Benedek, M., Wilkins, R. W., Jauk, E., Fink, A., Silvia, P. J., Hodges, D. A., Koschutnig, K., \& Neubauer, A. C. (2014). Creativity and the default network: A functional connectivity analysis of the creative brain at rest. Neuropsychologia, 64, 92-98.

https://doi.org/10.1016/j.neuropsychologia.2 014.09.019

Beaty, R. E., Chen, Q., Christensen, A. P., Qiu, J., Silvia, P. J., \& Schacter, D. L. (2018). Brain networks of the imaginative mind: Dynamic functional connectivity of default and cognitive control networks relates to openness to experience. Human Brain Mapping, 39(2), 811-821. https://doi.org/10.1002/hbm.23884

Beaty, R. E., Kenett, Y. N., Christensen, A. P., Rosenberg, M. D., Benedek, M., Chen, Q., Fink, A., Qiu, J., Kwapil, T. R., Kane, M. J., \& Silvia, P. J. (2018). Robust prediction of individual creative ability from brain functional connectivity. Proceedings of the National Academy of Sciences, 115(5), 10871092. https://doi.org/10.1073/pnas.1713532115

Beaty, R. E., Seli, P., \& Schacter, D. L. (2019). Network neuroscience of creative cognition: Mapping cognitive mechanisms and individual differences in the creative brain. Current Opinion in Behavioral Sciences, 27, 22-30. https://doi.org/10.1016/j.cobeha.2018.08.013 
Behzadi, Y., Restom, K., Liau, J., \& Liu, T. T. (2007). A component based noise correction method (CompCor) for BOLD and perfusion based fMRI. NeuroImage, 37(1), 90-101. https://doi.org/10.1016/j.neuroimage.2007.04 .042

Belden, A., Zeng, T., Przysinda, E., Anteraper, S. A., Whitfield-Gabrieli, S., \& Loui, P. (2020). Improvising at rest: Differentiating jazz and classical music training with resting state functional connectivity. Neurolmage, 207, 116384.

https://doi.org/10.1016/j.neuroimage.2019.11 6384

Benedek, M., Beaty, R., Jauk, E., Koschutnig, K., Fink, A., Silvia, P. J., Dunst, B., \& Neubauer, A. C. (2014). Creating metaphors: The neural basis of figurative language production. NeuroImage, 90, 99-106. https://doi.org/10.1016/j.neuroimage.2013.12 .046

Benedek, M., Jurisch, J., Koschutnig, K., Fink, A., \& Beaty, R. E. (2020). Elements of creative thought: Investigating the cognitive and neural correlates of association and biassociation processes. NeuroImage, 210, 10. https://doi.org/10.1016/j.neuroimage.2020.11 6586

Boden, M. A. (1998). Creativity and artificial intelligence. Artificial Intelligence, 103, 347356.

Bollen, K., \& Lennox, R. (1991). Conventional wisdom on measurement: A structural equation perspective. Psychological Bulletin, $110(2)$, 305-314. https://doi.org/10.1037/0033-2909.110.2.305

Bonnardel, N. (2002). Entrée: Créativité (pp. 95-97). Dictionnaire Des Sciences Cognitives. Armand Colin/VUEF.

Cavanna, A. E., \& Trimble, M. R. (2006). The precuneus: A review of its functional anatomy and behavioural correlates. Brain, 129(3), 564-583.

https://doi.org/10.1093/brain/aw1004

Cousijn, J., Zanolie, K., Munsters, R. J. M., Kleibeuker, S. W., \& Crone, E. A. (2014). The Relation between Resting State Connectivity and Creativity in Adolescents before and after Training. PLoS ONE, 9(9), e105780. https://doi.org/10.1371/journal.pone.0105780

De Dreu, C. K. W., Baas, M., \& Nijstad, B. A. (2008). Hedonic tone and activation level in the mood-creativity link: Toward a dual pathway to creativity model. Journal of Personality and Social Psychology, 94(5), 739-756. https://doi.org/10.1037/00223514.94.5.739

Dietrich, A. (2004). The cognitive neuroscience of creativity. Psychonomic Bulletin \& Review, 11(6), 1011-1026. https://doi.org/10.3758/BF03196731

Ding, X., Tang, Y.-Y., Cao, C., Deng, Y., Wang, Y., Xin, X., \& Posner, M. I. (2015). Shortterm meditation modulates brain activity of insight evoked with solution cue. Social Cognitive and Affective Neuroscience, 10(1), 43-49. https://doi.org/10.1093/scan/nsu032

Feng, Q., He, L., Yang, W., Zhang, Y., Wu, X., \& Qiu, J. (2019). Verbal Creativity Is Correlated With the Dynamic Reconfiguration of Brain Networks in the Resting State. Frontiers in Psychology, 10, 894.

https://doi.org/10.3389/fpsyg.2019.00894

Goles, T., \& Chin, W. W. (2005). Information systems outsourcing relationship factors: Detailed conceptualization and initial evidence. ACM SIGMIS Database, 36(4), 4767. https://doi.org/10.1145/1104004.1104009 Gupta, N., Jang, Y., Mednick, S. C., \& Huber, D. E. (2012). The Road Not Taken: Creative Solutions Require Avoidance of HighFrequency Responses. Psychological Science, 23(3), 288-294. https://doi.org/10.1177/0956797611429710

Haenlein, M., \& Kaplan, A. M. (2004). A Beginner's Guide to Partial Least Squares Analysis. Understanding Statistics, 3(4), 283297.

https://doi.org/10.1207/s15328031us0304_4

Hair, J. F., Hult, G. T. M., Ringle, C. M., \& Sarstedt, M. (2014). A Primer on Partial Least Squares Structural Equation Modeling (PLSSEM) (2nd ed.). Sage.

Harris, I. M., Egan, G. F., Sonkkila, C., TochonDanguy, H. J., Paxinos, G., \& Watson, J. D. G. (2000). Selective right parietal lobe activation during mental rotation. Brain, 123(1), 65-73. https://doi.org/10.1093/brain/123.1.65

Kenett, Y. N., Betzel, R. F., \& Beaty, R. E. (2020). Community structure of the creative brain at rest. NeuroImage, 210, 1-9. 
https://doi.org/10.1016/j.neuroimage.2020.11 6578

Lubart, T. I., Mouchiroud, C., Tordjman, S., \& Zenasni, F. (2003). Psychologie de la créativité (2e édition augmentée). Paris: Armand Colin.

Madore, K. P., Addis, D. R., \& Schacter, D. L. (2015). Creativity and Memory: Effects of an Episodic-Specificity Induction on Divergent Thinking. Psychological Science, 26(9), 1461-1468.

https://doi.org/10.1177/0956797615591863

Martindale, C. (2007). Creativity, primordial cognition, and personality. Personality and Individual Differences, 43(7), 1777-1785. https://doi.org/10.1016/j.paid.2007.05.014

Mechelli, A. (2004). Where Bottom-up Meets Top-down: Neuronal Interactions during Perception and Imagery. Cerebral Cortex, 14(11), 1256-1265. https://doi.org/10.1093/cercor/bhh087

Mednick, S. (1962). The associative basis of the creative process. Psychological Review, 69(3), 220-232. https://doi.org/10.1037/h0048850

Mendelsohn, G. A. (1976). Associative and attentional processes in creative performance1. Journal of Personality, 44(2), 341-369. https://doi.org/10.1111/j.14676494.1976.tb00127.x

Miyake, A., Friedman, N. P., Emerson, M. J., Witzki, A. H., Howerter, A., \& Wager, T. D. (2000). The Unity and Diversity of Executive Functions and Their Contributions to Complex "Frontal Lobe" Tasks: A Latent Variable Analysis. Cognitive Psychology, 4l(1), 49-100. https://doi.org/10.1006/cogp.1999.0734

Nijstad, B. A., De Dreu, C. K. W., Rietzschel, E. F., \& Baas, M. (2010). The dual pathway to creativity model: Creative ideation as a function of flexibility and persistence. European Review of Social Psychology, 2l(1), 34-77. https://doi.org/10.1080/10463281003765323

Ogawa, T., Aihara, T., Shimokawa, T., \& Yamashita, O. (2018). Large-scale brain network associated with creative insight: Combined voxel-based morphometry and resting-state functional connectivity analyses. Scientific Reports, 8(1), 1-11. https://doi.org/10.1038/s41598-018-24981-0
Paban, V., Deshayes, C., Ferrer, M.-H., Weill, A., \& Alescio-Lautier, B. (2018). Resting Brain Functional Networks and Trait Coping. Brain Connectivity, 8(8), 475-486. https://doi.org/10.1089/brain.2018.0613

Pidgeon, L. M., Grealy, M., Duffy, A. H. B., Hay, L., McTeague, C., Vuletic, T., Coyle, D., \& Gilbert, S. J. (2016). Functional neuroimaging of visual creativity: A systematic review and meta-analysis. Brain and Behavior, 6(10), e00540. https://doi.org/10.1002/brb3.540

Podzebenko, K., Egan, G. F., \& Watson, J. D. G. (2005). Real and Imaginary Rotary Motion Processing: Functional Parcellation of the Human Parietal Lobe Revealed by fMRI. Journal of Cognitive Neuroscience, 17(1), 24-36.

https://doi.org/10.1162/0898929052879996

Raichle, M. E. (2011). The Restless Brain. Brain Connectivity, 1(1), 3-12. https://doi.org/10.1089/brain.2011.0019

Riegel, K. F., Riegel, R. M., \& Levine, R. S. (1966). An analysis of associative behavior and creativity. Journal of Personality and Social Psychology, 4(1), 50-56. https://doi.org/10.1037/h0023522

Riou, J., Guyon, H., \& Falissard, B. (2016). An introduction to the partial least squares approach to structural equation modelling: A method for exploratory psychiatric research: PLS-SEM in Psychiatric Research. International Journal of Methods in Psychiatric Research, 25(3), 220-231. https://doi.org/10.1002/mpr.1497

Rominger, C., Papousek, I., Perchtold, C. M., Benedek, M., Weiss, E. M., Weber, B., Schwerdtfeger, A. R., Eglmaier, M. T., \& Fink, A. (2020). Functional coupling of brain networks during creative idea generation and elaboration in the figural domain. NeuroImage, $\quad 207, \quad 1-7$. https://doi.org/10.1016/j.neuroimage.2019.11 6395

Saggar, M., Quintin, E.-M., Bott, N. T., Kienitz, E., Chien, Y., Hong, D. W.-C., Liu, N., Royalty, A., Hawthorne, G., \& Reiss, A. L. (2017). Changes in Brain Activation Associated with Spontaneous Improvization and Figural Creativity After DesignThinking-Based Training: A Longitudinal 
fMRI Study. Cerebral Cortex, 27, 35423552. https://doi.org/10.1093/cercor/bhw171

Schuler, A.-L., Tik, M., Sladky, R., Luft, C. D. B., Hoffmann, A., Woletz, M., Zioga, I., Bhattacharya, J., \& Windischberger, C. (2019). Modulations in resting state networks of subcortical structures linked to creativity. NeuroImage, $\quad 195$, 311-319. https://doi.org/10.1016/j.neuroimage.2019.03 .017

Shen, W., Yuan, Y., Liu, C., Zhang, X., Luo, J., \& Gong, Z. (2016). Is creative insight taskspecific? A coordinate-based meta-analysis of neuroimaging studies on insightful problem solving. International Journal of Psychophysiology, 110, 81-90. https://doi.org/10.1016/j.ijpsycho.2016.10.00 1

Stevens, C. E., \& Zabelina, D. L. (2019). Creativity comes in waves: An EEG-focused exploration of the creative brain. Current Opinion in Behavioral Sciences, 27, 154-162. https://doi.org/10.1016/j.cobeha.2019.02.003

Takeuchi, H., Taki, Y., Hashizume, H., Sassa, Y., Nagase, T., Nouchi, R., \& Kawashima, R. (2012). The Association between Resting Functional Connectivity and Creativity. Cerebral Cortex, 22(12), 2921-2929. https://doi.org/10.1093/cercor/bhr371

Takeuchi, Hikaru, Taki, Y., Matsudaira, I., Ikeda, S., dos S. Kawata, K. H., Nouchi, R., Sakaki, K., Nakagawa, S., Nozawa, T., Yokota, S., Araki, T., Hanawa, S., Ishibashi, R., Yamazaki, S., \& Kawashima, R. (2020). Convergent creative thinking performance is associated with white matter structures: Evidence from a large sample study. NeuroImage, $210, \quad 9$. https://doi.org/10.1016/j.neuroimage.2020.11 6577
Tik, M., Sladky, R., Luft, C. D. B., Willinger, D., Hoffmann, A., Banissy, M. J., Bhattacharya, J., \& Windischberger, C. (2018). Ultra-highfield fMRI insights on insight: Neural correlates of the Aha!-moment. Human Brain Mapping, 39(8), 3241-3252. https://doi.org/10.1002/hbm.24073

Torrance, E. P. (2008). Torrance Tests of Creative Thinking: Norms-technical manual verbal forms $A$ and $B$. Scholastic Testing Service.

Torrance, E. P. (2017). Torrance Tests of Creative Thinking: Streamlined scoring guide for figural forms $A$ and $B$. Scholastic Testing Service.

Uddin, L. Q., Nomi, J. S., Hébert-Seropian, B., Ghaziri, J., \& Boucher, O. (2017). Structure and Function of the Human Insula: Journal of Clinical Neurophysiology, 34(4), 300-306. https://doi.org/10.1097/WNP.000000000000 0377

Wu, X., Jung, R. E., \& Zhang, H. (2016). Neural underpinnings of divergent production of rules in numerical analogical reasoning. Biological Psychology, 117, 170-178. https://doi.org/10.1016/j.biopsycho.2016.03. 011

Zhang, D., \& Raichle, M. E. (2010). Disease and the brain's dark energy. Nature Reviews Neurology, 6(1), 15-28. https://doi.org/10.1038/nrneurol.2009.198

Zhang, W., Sjoerds, Z., \& Hommel, B. (2020). Metacontrol of human creativity: The neurocognitive mechanisms of convergent and divergent thinking. NeuroImage, 210, 116572.

https://doi.org/10.1016/j.neuroimage.2020.11 6572

Zimmermann, P., \& Fimm, B. (1994). Tests d'évaluation de l'attention (TEA). Würselen: Psytest. 